\title{
Reflection of Interpersonal Relationships in Cognitions of Kyrgyz Imperative Paremias
}

\author{
Aigul Abdraeva1, Aida Zulpukarova², Dilaram Madaminova², Zamira Sabiralieva3, \\ Gulsana Abytova4, Nurzhamal Mapaeva4, Tolgonai Temiralieva4, Aiburak Shaimkulova ${ }^{5}$, \\ Nazira Karaeva6, Dinara Murzubraimova7, Zhypargul Abdullaeva ${ }^{8 *}$ (I)

\footnotetext{
${ }^{1}$ Department of Foreign Languages, Kyrgyz State University Named after I. Arabaev, Bishkek, Kyrgyzstan

${ }^{2}$ Department of Philology, Regional Studies, Mathematics and Computer Sciences, Osh State University, Osh, Kyrgyzstan

${ }^{3}$ Departemt of Russian Language Teaching Methodology, Osh State University, Osh, Kyrgyzstan

${ }^{4}$ Department of The Intercultural Russian Language, Osh State University, Osh, Kyrgyzstan

${ }^{5}$ Department of The Practical Course of The Russian Language and Culture of Speech, Osh State University, Osh, Kyrgyzstan

${ }^{6}$ Department of Kyrgyz Language Practical Course and Literature, Osh State University, Osh, Kyrgyzstan

${ }^{7}$ Department of English Language Grammar and Phonetics, Osh State University, Osh, Kyrgyzstan

${ }^{8}$ Science and Research Department, Osh State University, Osh, Kyrgyzstan

Email: *jypar.science@oshsu.kg
}

How to cite this paper: Abdraeva, A., Zulpukarova, A., Madaminova, D., Sabiralieva, Z., Abytova, G., Mapaeva, N., Temiralieva, T., Shaimkulova, A., Karaeva, N., Murzubraimova, D., \& Abdullaeva, Z. (2021). Reflection of Interpersonal Relationships in Cognitions of Kyrgyz Imperative Paremias. Open Journal of Modern Linguistics, 11, 484-496.

https://doi.org/10.4236/ojml.2021.113036

Received: June 4, 2021

Accepted: June 26, 2021

Published: June 29, 2021

Copyright $\odot 2021$ by author(s) and Scientific Research Publishing Inc. This work is licensed under the Creative Commons Attribution International License (CC BY 4.0).

http://creativecommons.org/licenses/by/4.0/ (c) (i) Open Access

\begin{abstract}
Research relevance in this article is focused on insufficient knowledge of stable imperatives-prohibitions in the Kyrgyz language, which occupy an important place in the composition of the ethnos paremias and play a significant role in regulating the relationship of people in society. Study of imperatives is necessary for linguistic paremiology, the theory of morality and speech culture. Research purpose in this work is to determine the cognitive-linguistic content, structural-semantic types and communicative-speech functions of precedent imperatives-prohibitions in Kyrgyz language. Within the framework of this goal-setting, main cognitemas of imperatives were established, the ways of objectification of these cognitions with the help of corresponding paremic turns were characterized. The originality of the paradigmatic-syntagmatic structure of imperative formulas revealed, constants and variables in the paremic sayings in the language were distinguished. The cognitive-imperative essence and their role in strengthening the ethnounity were described. Above research results can be used in the study of the syntax in the Kyrgyz language at primary and higher education institutes.
\end{abstract}

\section{Keywords}

Cognitema, Invariant and Variant, Proposition, Transformation, Constant and Variables, Generalized Personal Sentence 


\section{Introduction}

Imperative is a polyfunctional term of Latin origin (imperium means "power, empire", and word imperativus "imperative") is widely used in human life and branches of science, in linguistics, logic, sociology (Gumperz \& Cook-Gumperz, 2008), pedagogy, psychology, ethics, theology and philosophy (Swales et al., 1998; Evans et al., 2020).

The imperative is a linguo-cognitive tool that directs and restricts people's livelihoods, regulates their behavior and relationships in society and contains generally accepted norms and rules of the community, designed to strengthen and positive social life in general. The imperative is a fairly well-studied social category. I. Kant called it the law of morality (Kant, 1999: pp. 152-153), which limits the will and freedom of a person to perform the function of command in society. F. Nietzsche's idea appears straightforward enough and provides the unique conditions (Nietzsche, 2000: pp. 5-12).

The moral imperatives of humanity have a long history. The most ancient of them were reflected in the religion attitudes, Judaism, Taoism, Buddhism, Christianity, Islam and other religions and played a very positive role in the moral growth of mankind (Bible, 1991: pp. 12-16; Dalai Lama XIV, 2000: pp. 96-98; Abdulatov, 2006: pp. 93-95; Zulpukarov et al., 2018: pp. 183-189, 653-668; Zulpukarov et al., 2019: pp. 304-306, 607; Abdraeva \& Madaminova, 2018: pp. 6-11).

In the modern world, social imperatives serve as the moral code of mankind, are replenished with new rules and norms related to ecology, dehumanization, the flu epidemic and other negative processes in the world (Boutilier \& Bahr, 2020), but are specially studied as phenomena of consciousness, morality, culture and language (Bianco \& Cobo, 2019). In this context, the appeal to the Kyrgyz moral imperatives and their linguistic representations becomes a very important problem that requires linguistic comprehension and coverage (Musaev, 2016). Until now, this issue has not been the subject of linguoculturological consideration.

Consequently, relevance of this article considers the lack of Kyrgyz moral imperatives study and their types with functions based on the material of common paremias-prohibitions in language. The article aims to characterize socio-cultural imperatives-prohibitions in Kyrgyz ethnos, aimed at regulating and strengthening the relationship between members of society in modern conditions.

\section{Research Methods and Materials}

The article analyzes Kyrgyz moral imperative forms from the cognitive linguistic and cultural linguistics points of view. All of them drawn up in the form of generalized personal proposals. Their predicates complete phrases and contain negative affixes -ba/-be/-bo/-be/-pa/-ne/-po/ne "not", which are expressing the prohibition. The factual material is taken from research on linguoparemiology, from collections of Kyrgyz proverbs, sayings (Ibragimova \& Asrankulova, 2016: pp. 5-40; Koichumanov \& Kadyrov, 2012: pp. 459-490; Akmataliev et al., 2011: 
pp. 161-162; Ibragimov, 2008: pp. 79-86; Yudakhin \& Sarbagyshev, 2011: pp. 18-21, 92-93). The research was carried out using comparative, descriptive and transformational methods. The work distinguishes between constant and variable, invariant and variable imperative signs of imperatives. General and constant values of paremias integrate particular, concrete, unite them within their limits, act in relation to them as invariant principles. We, following E.V. Ivanova (2006: pp. 97-99), call such invariant values cognitems. Cognitema is a unit of memory, exists in the mind of a person, contains the generalized meaning of a saying. Each of the cognitives distinguishes within itself private, specific cognitives, and materializes in the proverbial signs of the language. Cognitemes in the Kyrgyz speech etiquette and ways of their interpretation in language, as well as types of imperatives-prohibitions in the linguistic and linguistic-ethnocultural aspects (Zulpukarov et al., 2018; Abdraeva et al., 2021) were analyzed. In characterizing of ethno-mental content of imperatives-prohibitions, we rely on the works of Kyrgyz ethnographers (Ibragimova \& Asrankulova, 2016, p. 203-221; Akmataliev, 2000, p. 256-279; Abdyrazakov, 2018: pp. 211-238). The definition of the types and varieties of paradigms and parasyntagmas is based on the ideas and principles of the paradigmatic-syntagmatic approach (Zadorozhny, 1983: pp. 28-30).

\section{Results and Discussion}

The Kyrgyz mentality divides the ethnos into two categories: 1) uluular "senior/respected/revered/elderly (people)" and 2) kichulur "younger/youth/young (people)". This social dichotomy is consistently accounted in imperative paremias and serves as the basis for determining the relationship between representatives of two age categories of an ethnic group.

In the mental and linguistic picture of the Kyrgyz people, there is a cognitive topic "Elders must be respected", which requires young people to respect people who are higher in age, knowledge, experience, position, status and other parameters. This general statement is broken down into several private statement requirements, which are formalized specifically in the form of prohibitions.

\subsection{Do Not Argue with Your Elders}

The following imperative pairs are suitable for this semantic formula: 1) Uluunun/uluu adamdyn zholun kesip otpoyt "Do not cross the road for older/older people”. 2) Uluularga kayasha aitpa "Do not quarrel with your elders". 3) Uluulardan soz talashpa "Do not argue with your elders". 4) Uluulardyn suzun bolboyt "Do not interrupt the conversation of the elders". 5) Uluulary shyldyndabayt "Do not laugh at the elders". 6) Uluulardyn kuzunchu zhaisyz kulby "They do not laugh for no reason in front of their elders". 7) Chongo chon ayagyndy korsotpo "Do not show the respected big (strength)". 8) Zhol zhurgundo uluudan ozbo "Do not overtake the elders on the road". 9) Uluu menen urushpayt "Do not swear with the elders/do not swear". 10) Uluu kishige byrok tayanyp zhoop berbeit "They do not respond to their elders, leaning on their side". 11) 
Uluunun sozun urmatta, uurular menen sirdashpa "Honor the words of your elders, do not share your secrets with thieves". The content of all imperatives is motivated. The older generation is leaving, and a new one is coming to replace it. The new generation should be respectful of the outgoing one. Tomorrow the new generation will give way to the next. This is the law of society. An understanding of this law is embedded in the content of each imperative. There is negation in all expressions. In some examples, the negation affix appeared in the interposition, in the middle of the imperative $(1,4,9,10)$, in others it is located at the end of the imperative of the phrase. In command formulas, it is not recommended for elders to cross the road (1), it is forbidden to argue, to sharply express their disagreement, to answer them rudely (2), it is required not to wedge into the conversation of adults, not to interfere with their conversation and not to interrupt them $(3,4)$, not to do elders are the subject of ridicule, mockery, if they are mistaken in actions, words, thoughts (5), do not laugh in front of them without special reasons, without reason (6), do not show elders hot temper, incontinence, pugnacity, i.e. "Bigfeet" (7), do not walk or drive in front of respected people on the road (8), when talking with them, do not show arrogance, arrogance, resting his hands on his hips $(9,10)$. Only the last example has a complex structure (11). The denial is in the second part. The first part of the phrase, which requires respect for the elderly, refers to general cognition.

\subsection{Compete with Equals}

The next cognition is "Compete with equals". It is represented in the poems of the poet T. Satylganov:

Er zhigit, kuroshpogun balban menen;

Balbandy zhyga albaysyn chalgan menen;

"Young man, do not fight a strong man,

The strong man did not fall off with a footboard."

Of course, in translation, the poetics of lines lost their harmony, rhythm and rhyme. The main idea of the poet lies in the imperative form of kuroshpogun balban menen "Do not fight with the strongman" and corresponds to the content of the above-mentioned cogniteme.

Within the framework of the cogniteme "Compete with equals", we distinguish three particular cognitemes: 1) "Do not compete with smarter ones than yourself"; A) 1) Akilduu menen arbashpa "Do not quarrel with the wise". 2) Azuuluu menen arbashpa "Do not quarrel with toothy ones". 3) Taalayluu menen taylashpa "Do not fight the happy". 4) Tektuu menen tebishpe "Do not kick with the noble ones". 5) Tuptuu menen turtushpo "Do not push with the mighty". Arstandan zhem talashpa "Do not compete with the lion because of the food". B) 1) Azuuluu menen alyshpa, alduu menen karmashpa "Do not fight with the toothy, do not fight with the strong". 2) Baktyluu menen bastashpa, taalayluu menen talashpa "Do not compete with the happy, do not compete with the lucky ones". Taalayluu menen taylashpa, baktyluu menen bastashpa "Do not 
fight the lucky ones, do not compete with the happy ones". 3) Alp konulun kaltyrba, at arkasyn zhoorutpa "Do not offend the giant hero, do not bring the horse's back to abrasions". 4) TptyY menen turtushpo, tektuu menen tebishpe "Do not push with the mighty, do not kick with the noble ones". 5) Arstandin oozunan jem talashpa: ozun jem bolosun "Do not pretend to be food in the mouth of a lion: you yourself will become its food", etc. The advice contained in imperative paremias is needed by young people. She is well informed about life, about the relationship of people, living in the conditions of globalization and the accelerated dissemination of information. It is necessary to know the attitudes and imperatives of her ancestors, reflected in their laconic and figurative expressions, and be guided by them in life.

Many of the above speech formulas have an identical structure, are modeled and brought under the general scheme and cognition "Compete with equals". The predicates of all paremias include the negation -pa, -ba, -bo "not". The consonance of words in the structure of proverbs is noticeable. Some paremias are built in the form of simple sentences (A), others in the form of complex sentences (B). Parts of complex imperatives are concurrent. These properties of imperatives can be visualized in the form of diagrams (Figure 1).

All phrases are the same. Only the last example (B-5) has a slight deviation but obeys the general formula. Examples forms of three paradigms:

1) six words with the general meaning of "superior person"; in the first five words the seme "possession" is contained in their affixal part (in the proverb, the name of an animal means a person);

2) the postposition is changed " $s$ ", used 6 times;

3) six predicates-prohibitions with affixes of negation (final affixes) and compatibility (affix -ш/-is/-ush).

There is a contradictory unity between the cognitive and its representations: cognitema is positive, expresses permission, permission, and its exponents contain negation, prohibition. Six proverbs form one parasyntagm, consisting of a combination of three paradigms, and contain one cognitive meaning.

The imperatives of group B possess the same paradigmatic-syntagmatic properties. However, each of them includes pairwise connected simple sayings. Their structure can also be represented schematically (Figure 2).

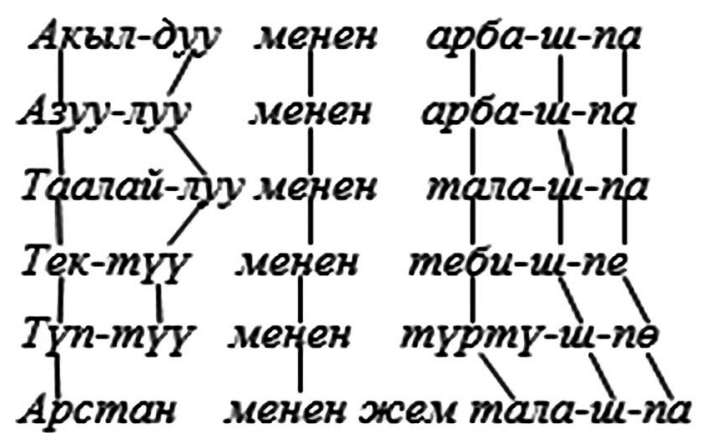

Figure 1. Properties of visualized imperatives. 


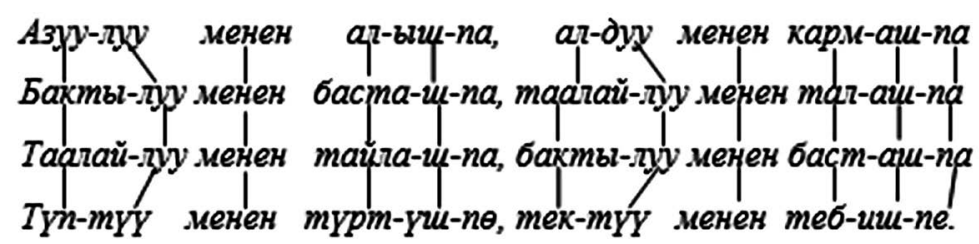

Figure 2. B group imperatives.

Only the last example (B-5) on the list does not fit this formula. These four proverbs are complex and consist of a combination of the previous simple ones. Each part of complex formations conveys the invariant meaning of "Compete with equals". The proverbs represent eight exponents of this total value.

Life is a struggle when the time has come for contests, elections, auditions, ratings. In these conditions, especially for young people, it is useful to know the generally accepted ethnos wise establishments, which presuppose balanced intentions, goals and actions, to objectively assess their own and others' merits, to understand the need to build up their potential and strengthen their capabilities.

The Kyrgyz mentality believes that an extraordinary person simply should not enter into a competition with a person from a respected, revered family, with a representative of a large or strong clan (A-4), with a person with fundamental knowledge, strong character and support (A-5), with an intelligent challenger who knows how to reason, persuade and mobilize (A-1), with a tough, formidable and merciless person (A-2, 6), with a successful, successful and lucky face (A-3). We do not think that there is a call to passivity in these imperatives. They have a call to balance, which implicitly contains the idea "The smart must compete with the smart, the strong with the strong".

In the proverbs of group B, these same imperatives are doubled, strengthened and in pairs express the cognitive meaning "Compete with equals".

Among the Kyrgyz formulas of morality, many imperative sayings are expressing the cognition "One must respect a person". This constant meaning exists in the minds of each ethnos, representative and is reflected in numerous paremic expressions, is an important element of the cognitive-linguistic picture of the people, but it, of course, is understood, actualized and implemented by different people in different ways. This cognition calls on the representatives of the ethnos to philanthropy, humanism and is displayed very productively. Our card index contains 96 proverbial representations of the "We must respect a person" cognition. Of these, we have selected only 17 proverbial units containing imperatives-prohibitions: 1) Adamdy ailanba/tegerenip churkaba "Do not circle around a person". 2) Adamdy attap otpo "Do not step over a person". 3) Kishige artyңdy salba/Adamga dalygy salyp oturba "Do not sit with your back to a man". 4) Adamdy's chump chappa "Don't hit a man on the head". 5) Chisinau shypyrgy menen urba "Don't hit a man with a broom". 6) Adamdy malcha sanaba/sөөтөуүң menen sanaba "Do not consider people like cattle with your finger". 7) Kishini iyininen baspa/kemsintpe "Do not push a person on the shoulders/Do not humiliate a person/Do not consider a person inferior to yourself". 
8) Adamdyn aiybyn izdebe/publisher bolbo "Do not look for flaws in a person". 9) Chisinau bashynan zhazdykty suurup albayt "They do not pull a pillow from under a person's head". 10) Kishige iңirde kөңүl aitpa "Do not say condolences to a person in the evening". 11) Kishi kelatkanda tamakty zhashyrbayt/zhashyryp katpayt "They do not hide food when a person walks". 12) Adam elgen kyny $\mathrm{kir} /$ bash zhuubayt "On the day of death, a person is not washed/their hair is not washed". 13) Adamga zhakshylyk kyluunu unutpa "Do not forget to do good to a person". 14) Adamga bychak kezebeit "They will not guide a knife to a man". 15) Adamdy Cordobo, Akmakty Bordeaux "Do not insult a man, do not feed a fool." 16) Adamcha tuulup, aibancha zhashaba "Having been born as a man, do not live like a beast". 17) Chisinin baaryn $\theta z$ tukumuң menenen cinebegin "Do not measure all people by their offspring".

All examples contain negative predicates. In a number of cases, the prohibitions are categorical, designed in the form of imperative clauses and have negative affixes at the end -ba/-pa, etc. $(1-8,10,13,15,16)$. Some imperatives are built in the form of generalized personal statements $(9,11,12,14)$. In this case, the affixes of negation are located in the middle of the verbal predicates: al-ba-y-t(al- "take"), zhashyr-ba-y-t (zhashyr- "hide"), kat-pa-y-t (kat- "hide"), zhuu-ba-y-t (zhuu- "wash, wash"), keze-be-y-t (keze- "instruct, aim"), behind negation (-ba, -pa, -be) comes the adverbial affix -th and the personal-predicative affix of the 3rd person -t "he, she".

All imperatives call for respectful treatment of a person. There are numerous idioms in the language that echo these proverbs in semantics, laconically and figuratively conveying the importance of mutual respect of people: syiga syy "treat a treat", urmatka urmat "respect respect", zhakshylykka zhakshylyk "good good", etc. There are idioms that are opposite to these in meaning, but aimed at positive results, warning against negative actions: basyntkan basynat "the humiliating one will be humiliated", the kordogon kor of the swamps "the one who insults will be offended", the kynagan kyinalat "the torturer will become tortured" and so on. In idioms, the imperative is present implicitly, implicitly.

In each of the 17 imperatives, the words adam and kishi "man" are used as exponents of the object of the sayings. The first word is of Semitic (Heirean, Arabic), and the second is of Eastern (Chinese) origin (Abdraeva et al., 2017: p.15; Zulpukarov, 2016: pp. 141-142). All imperatives call for a respectful attitude towards people, for the observance of generally accepted principles and rules of human relations. The popular mentality condemns when young people circle and run around sitting and standing people, creating inconveniences for them, causing dizziness and distracting them from the conversation (1). Kirghiz does not allow to step over a person who is resting or sleeping on the floor, considering such an act a sign of bad manners and rudeness (2). In the Kyrgyz linguistic culture, it is forbidden to sit or stand with your back to a person, which is assessed as a disrespectful attitude towards him (3). To hit a person on the head, beat him with a broom is considered an insult, gross disrespect $(4,5,14)$. The Kyrgyz do not even consider horses as an index finger (Koichumanov \& Kady- 
rov, 2012: pp. 126), and counting people in this way is recognized as immoral behavior that humiliates their dignity and equates them with things or small livestock (6). Putting pressure on the shoulders of a child or other person is also alien to the Kyrgyz mentality and is understood as a desire to humiliate him, to stop his mental and physical growth (7). The Kyrgyz environment strongly condemns the behavior of people who seek, find and disseminate information about the shortcomings, weaknesses, mistakes of others, distort and exaggerate them in the eyes of the public (8). They call such people slanderers.

When a person dies, a pillow is removed from under his head. This is a ritual. Therefore, it is forbidden to do this when a person is sleeping (9). Belief establishes an analogy between two cases, influencing the will and behavior of people.

The next imperative contains the requirement to visit the family of the deceased, express condolences and read a prayer for the deceased only in the morning (10). The Kyrgyz mentality condemns those who spare food for people, hides it from guests or neighbors (11) and always approves of hospitality. According to the belief of the Kyrgyz, during a commemoration in the family, neighbors or clan should not wash, swim and wash their hair (12). The next imperative is of general importance. He demands that people do only good to others so that in their mind there is always a readiness to do good deeds (13). It is believed that frightening a person with a knife or other similar instrument (14) and insulting him (15) are inhuman actions, and it is inappropriate to treat a fool abundantly (15).

According to the Kyrgyz, one should live not by animal rules, but by human ones (16), to evaluate people and their actions not from the point of view of narrow interests, but universal ones (17). All this suggests that the Kyrgyz strive to ensure that their representatives in their behavior adhere to generally accepted norms and respect each other.

\subsection{Do Not Get Close to the Unworthy}

The Kyrgyz mentality divides its representatives into two categories: worthy and unworthy. The Kyrgyz linguistics consider the bearers of all positive qualities to be worthy, and the bearers of negative characteristics as unworthy. The dignity of people is determined from different positions and different angles. The same person can be worthy in one position, unworthy in another position. For example, several simple imperatives contain the cogniteme "Do not get close to the unworthy": 1) It's a pity to change the zarmaktashpa "Do not be friends with the lazy". 2) Alky buzuktun artyn ishenbe "Do not trust the shameless". 3) Antkorgo zhakyn konbo "Don't stop (for a summer vacation) next to a slanderer" (about nomads). 4) Zhalganchy menen mamile tyzbe "Do not mess with a liar". 5) Buzuku menen mudashpa "Do not share (your joys and sorrows) with the dissolute". 6) "Kasydyn yyunday chach aldyrba "Do not get your hair cut in the enemy's house". 7) Ozhor adam menen kuroshpo "Do not compete with the stubborn". 8) Saran adam menen maekteshpe "Do not talk to greedy". 9) Alanyn izin baspa "Don't follow the dishonest". 10) Turkoy menen soz talashpa "Do not ar- 
gue with the illiterate uneducated".

National mentality refers to the category of unworthy people as those who have moral, psychological and behavioral shortcomings, warns their representatives against communication and intimacy with loafers, parasites (1), shameless, depraved people (2), slanderers, liars $(3,4)$, shameless and dissolute people (5). The Kyrgyz are convinced that you cannot trust your enemies with your life (6) and that you should not compete with people who are uncompromising, intractable (7). In their opinion, one should always stay away from extremely stingy and dishonest people $(7,8)$, there is little point in talking with dark, illiterate people (9). Cognitema "Don't get close to the unworthy" is sometimes part of complex formations and becomes part of the more developed cogniteme "Don't get close to the unworthy, don't avoid the worthy". Here are some examples: 1) Zhamanga zhakyndaba, zhakshydan alystaba "Do not get close to the unworthy, do not move away from the worthy". 2) Zhamanga zhakyndyk kylba, zhakshyga zhattyk kylba "Do not show closeness to the unworthy, do not show enmity towards the worthy". 3) Zhamanga zhalynba, zhakshyga taarynba "Do not beg the unworthy, do not be offended by the worthy". 4) Zhamanga үңүlbө, zhakshydan tүнүlbe "Do not look at the unworthy, do not part with the worthy". 5) Zhamandan kach, zhakshydan zhazgan "Run away from the unworthy, honor the worthy". 6) Zhakshyga zhanash, zhamandan adash "Be equal to the worthy, run away from the unworthy". 7) Zhakshydan kachpa, zhamanga baspa "Do not run away from the worthy, do not approach the unworthy".

Let us analyze the last two imperative pairs in more detail in Figure 3.

The proposal has a complex structure and has two imperative predicates. Abbreviations are accepted in the scheme: PI-predicate-imperative, PI1 conveys a positive requirement, PI2-negative (negation is expressed lexically). SA is a substantiated adjective word, OD is an object in a dative, $\mathrm{OA}$ is an object in an ablative, $\mathrm{P}$ is a paremia, a proverb.

The two parts of the saying are generally similar, the predicates are phonetically consonant, rhymed, and express the command. The names of antonymic objects (OD) also have the same beginning (zha-). The phrase is based on the sound a: out of ten vowels, nine sound the same.

The semantics of the aphorism is fully consistent with the cognition established above. However, the proverb is literally translated a little differently: "Be equal to the worthy, run away from the unworthy." Words denoting worthy and unworthy people have a generalized meaning: worthy means many positive signs of a person, and unworthy means many of his shortcomings.

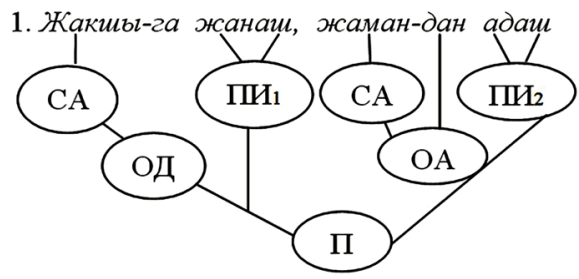

Figure 3. Imperative pairs analysis. 
In both parts of the proverb, the key position is occupied by predicates-imperatives, coordinating within their limits the meaning of the generalized subject-producer of the action, the nature, direction and performance of the action, the imperativeness of intonation and the general meaning of the phrase.

The next representative cogniteme expresses the imperative more categorically, having in its structure the affix of negation-na "not".

Symbols and abbreviations in this table are the same as in the first. Only ablative and dative are reversed. The ablative object is the owner of positive signs, the date object is the owner of negative ones. The phrase has the meaning "Do not run away from the worthy, do not approach the unworthy". And here there is a sound harmony, rhythmic similarity and rhyme.

In two proverbs, the parts are synonymous: 1) zhakshyga zhanash "be equal to the worthy one" and zhakshydan kakpa "do not run away from the worthy one"; 2) zhamandan adash "run away from the unworthy" and zhamang basp "do not approach the unworthy". This speaks of the semantic parallelism of the parts of winged expressions. And at the same time, the presence of a chiasmatic relationship between the paremic forms expressing the meanings of the object is noted in Figure 4.

As it is seen, in the proverb $A$ the dative is used in the first part, the ablative in the second part, in the proverb $\mathrm{B}$, on the contrary, the ablative is used in the first part, the dative in the second part.

In the precedent imperatives being compared, there are common words (zhaman-zhaman, zhakshy-zhakshy), antonyms zhakshy "good, worthy"-zhaman "bad, unworthy"; zhanash "equal"-kach "run away", adash "run away"-bass "draw near", the affix dativa -ga-the affix ablative -dan (Figure 5).

The intersection of case forms strengthens the constructive and semantic unity of the two imperatives. The people demand from their representatives that they be in good, close and trusting relationships with the owners of the best moral qualities and keep their distance from people with a negative nature and immoral character traits.

Some complex imperative paremias do not oppose two categories of people to

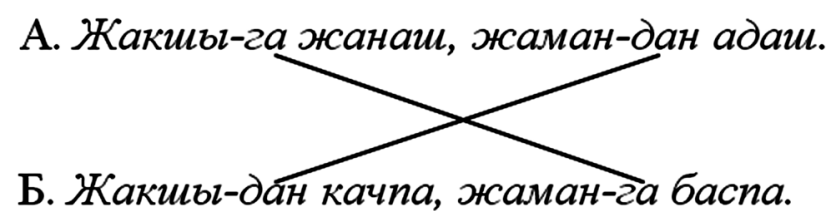

Figure 4. Chiasmatic relationship between the paremic forms.

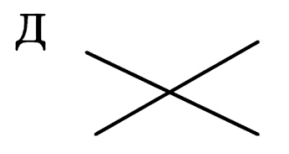

A

A

Д
$-2 a$

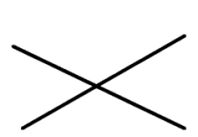

$-\partial a H$ $-\partial a H$

$-2 a$

Figure 5. Chiasm of cases in separate types. 
each other, do not contain an antithesis, but fully and two-fold represent the cognition "Do not get close to the unworthy". 1) Joldosh bolbo korkokko, ish kyldyrba chorkokko "Do not go out on the road with a coward, do not entrust things to an inept/foolish man". 2) Ish tapshyrba of a pathetic, akyl aytpa chalpoogo "Do not entrust business to a bummer, do not give advice to inaudible". Both proverbs consist of two parallel simple parts that represent the same cognition, are built in a poetic form, have signs of sound harmony, rhythm and rhyme. The imperatives are located in the middle and end with negation affixes (-bo, -ba, -pa). The paremias contain a warning against mistakes that can be caused by friendship and cooperation with cowards (1-1), entrusting a responsible business to incapable people (1-2) or lazy workers (2-1), as well as instructions, advice to arrogant, inept young people (2-2).

Practical application in this work is based on importance and role of paremias-imperatives in society life, regulating members behavior and educating young people to follow the generally accepted human relation norms.

\section{Conclusion}

The foregoing allows us to draw some general conclusions: 1) The imperative is a category of morality, created and used by the people as a means that directs and regulates the life of an individual in society. 2) Each imperative has a propositional meaning and generalizes the experience and knowledge of an ethnic group. 3) By the generality of semantics, imperatives are combined into cognitemes. Cognitema is the constant value of one or more paremias. Within the general cogniteme, private cognitemes are distinguished.

In the process of analyzing the imperative formulas in the Kyrgyz language: 1) the essence of the imperative paremias and their role in regulating the relationship of people in society were determined; 2) the main types and models of imperative cognitions are highlighted; 3 ) the ways and means of proverbial objectification of these cognitions are characterized; 4) the organizing function of negation affixes is shown in the composition of proverbial predicates-imperative forms of the verb; 5) demonstrates the paradigmatic-syntagmatic structure of paremias-prohibitions in the language.

\section{Conflicts of Interest}

The authors declare no conflicts of interest regarding the publication of this paper.

\section{References}

Abdraeva, A., Marazykov, T., Choibekova, N., Madaminova, D., Zulpukarova, A., Sagyndykova, Z., Ermekbaeva, N., Sabiralieva, Z., \& Abdullaeva, Z. (2021). Cognitemes in the Kyrgyz Speech Etiquette and Ways of Their Interpretation in Language. Open Journal of Modern Linguistics, 11, 249-261. https://doi.org/10.4236/ojml.2021.112020

Abdraeva, A. T., \& Madaminova, D. B. (2018). Kyrgyz Lingvo-Ethnocultural Prohibitions from the Point of View of Turkish and English Mentality. Modern Trends in the De- 
velopment of Science and Technology. Periodic Scientific Collection. Belgorod, Part I (pp. 6-11).

Abdraeva, A. T., Madaminova, D. B., \& Zulpukarova, A. K. (2017). Concept as a Category of Epistemology and Linguistics. Modern Trends in the Development of Science and Technology (pp. 3-5, 12-14).

Abdulatov, A. A. (2006). Some Problems of Describing Paremias for Cognitive and Pedagogical Purposes (119 p.). Osh.

Abdyrazakov, K. (2018). Kaada muras (356 p.). Bishkek.

Akmataliev, A. S. (2000). Kyrgyzdardyn koonorboos doolottoru (348 p.). Bishkek.

Akmataliev, A. S., Sakieva, N., Asanova, Zh., \& Attokurova, A. (2011). Ata-babalar taberigi: Kyrgyzdyn adep-ahlak, salt-sanaa, orp-adat, yrym-zhyrym zhana zhurulgulur zhyinagy (724 p.). Bishkek.

Bianco, R., \& Cobo, O. (2019). The Linguistic Integration of Refugees in Italy. Social Sciences, 8, 284. https://doi.org/10.3390/socsci8100284

Bible (1991). Stockholm (640 p.).

Boutilier, R. G., \& Bahr, K. (2020). A Natural Language Processing Approach to Social License Management. Sustainability, 12, 1-12. https://doi.org/10.3390/su12208441

Dalai Lama XIV (2000). Buddhism of Tibet. Buddhism. Four Noble Truths (pp. 91-127). Moscow: Kharkov.

Evans, R., Sergot, M., \& Stephenson, A. (2020). Formalizing Kant's Rules. Journal of Philosophical Logic, 49, 613-680. https://doi.org/10.1007/s10992-019-09531-X

Gumperz, J. J., \& Cook-Gumperz, J. (2008). Studying Language, Culture, and Society: Sociolinguistics or Linguistic Anthropology? Journal of Sociolinguistics, 12, 532-545. https://doi.org/10.1111/j.1467-9841.2008.00378.x

Ibragimov, M. (2008). Kyrgyz makal, lakap, uchkul sozdur (640 p.). Bishkek.

Ibragimova, K., \& Asrankulova, B. (2016). Uluulardan taberik(256 p.). Bishkek.

Ivanova, E. V. (2006). Peace in English and Russian Proverbs (278 p.). St.Pb.

Kant, I. (1999). Foundations of the Metaphysics of Morality (713 p.). Moscow: Nauka.

Koichumanov, J., \& Kadyrov, Y. (2012). Proverbs, Sayings, Winged Expressions, Wise Thoughts (540 p.). Bishkek: Biyiktik plus.

Musaev, S. (2016). Kyrgyz Linguistics. Problems of Modern Science and Education, 20, 52-56.

Nietzsche, F. (2000). Morning Dawn. Revaluation of the Valuable (673 p.). Minsk: Fun Science.

Swales, J. M., Ahmad, U. K., Chang, Y.-Y., Chavez, D., Dressen, D. F., \& Seymour, R. (1998). Consider This: The Role of Imperatives in Scholarly Writing. Applied Linguistics, 19, 97-121. https://doi.org/10.1093/applin/19.1.97

Yudakhin, K. K., \& Sarbagyshev, N. M. (2011). Kyrgyz Proverbs and Sayings: From the Collection of Academician (199 p.). Bishkek.

Zadorozhny, M. I. (1983). Parasyntagmatics as One of the General Relations between the Lexical Units of the Language. Study and Teaching of the Russian Language in Bilingual Conditions. Lexicon and Phraseology Part I (pp. 28-30). Frunze.

Zulpukarov, K. Z. (2016). Introduction to Sino-Kyrgyz Comparative Linguistics (748 p.). Bishkek.

Zulpukarov, K. Z., Abdulatov, A. A., Kamardinova, U. N., Kozhoeva, G. Zh., Ergeshova, S. B., \& Eshmanova, S. K. (2018). Actual Problems of Linguopoetics and Linguopare- 
miology (828 p.). Bishkek.

Zulpukarov, K. Z., Muradymova, E. N., Ormokeeva, R. K., Bolotakunova, G. Zh., \& Amiraliev, S. M. (2019). Linguistic Anthropocentrism: Problems, Searches and Solutions (743 p.). Bishkek. 